\title{
High-Content High-Throughput Assays for Characterizing the Viability and Morphology of Human iPSC-Derived Neuronal Cultures
}

\author{
Oksana Sirenko, ${ }^{1}$ Jayne Hesley, ${ }^{1}$ Ivan Rusyn, ${ }^{2}$ \\ and Evan F. Cromwell ${ }^{1}$ \\ ${ }^{1}$ Molecular Devices, LLC, Sunnyvale, California. \\ ${ }^{2}$ Department of Veterinary Integrative Biosciences, Texas ActM \\ University, College Station, Texas.
}

\begin{abstract}
Development of quantitative high-throughput in vitro assays that enable assessment of viability and morphological changes in neuronal cells is an active area of investigation in drug discovery and environmental chemical safety assessment. High-content imaging is an emerging and efficient tool for generating multidimensional quantitative cellular readouts; in addition, human induced pluripotent stem cell (iPSC)derived neurons are a promising in vitro model system that emulates both the functionality and behavior of mature neurons, and they are available in quantities sufficient for screening workflows. The goal of this study was to develop high-content imaging and analysis methods to assess multiple phenotypes in human iPSC-derived neuronal cells. Specifically, we optimized cell culture, staining, and imaging protocols in a 384-well assay format and improved laboratory workflow by designing a one-step procedure to reduce assay time and minimize cell disturbance. Phenotypic readouts include quantitative characterization of neurite outgrowth and branching, cell number and viability, as well as measures of adverse effects on mitochondrial integrity and membrane potential. To verify the robustness of the workflow, we tested a series of compounds that are established toxicants. We report concentrationresponse effects of selected test compounds on human iPSC-derived neuronal cells and illustrate how the proposed methods may be used for high-content high-throughput compound toxicity screening and safety evaluation of drugs and environmental chemicals.
\end{abstract}

\section{INTRODUCTION}

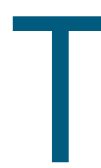

he nervous system can be subject to the toxic effects of environmental chemicals and pharmaceutical drugs. Exposure to neurotoxic compounds in prenatal and postnatal stages of mammalian development can result in alterations in the function of the nervous system later in life. A number of human neurological disorders have been associated with early-life exposure to chemicals. ${ }^{1,2}$ In addition, neurotoxicity is an adverse drug reaction of concern to the pharmaceutical industry. ${ }^{3}$ Accordingly, there is a high demand for the development of predictive and disease-relevant cell-based assays that can be used for the efficient assessment of chemicals and drug candidates in a high-throughput quantitative screening format. ${ }^{4,5}$

The development of in vitro models of the human central nervous system or peripheral nervous system has been challenging. ${ }^{6}$ The complexity, in terms of the number and interconnectivity of multiple cell types, maturity, and highly differentiated state of most cells of the mammalian nervous system is difficult to replicate in cell-based models. Specifically, it is crucial that in vitro assay readouts not only evaluate cell viability, but also enable assessment of cell morphology and neuron-specific cell functional activity. High-content imaging is a powerful tool that can provide information on multiple morphological parameters for such assays. ${ }^{7-9}$

A number of in vitro models have been proposed for neurotoxicity testing. ${ }^{10-12}$ Immortalized cell lines, such as PC12 and human neuroblastoma cells are widely employed. ${ }^{11}$ However, these models have yielded low predictivity for toxicity assessment, likely due to their lack of complete neuronal functionality and poor differentiation. ${ }^{11,13} \mathrm{Cul}-$ tures of primary neurons (e.g., freshly isolated or cryopreserved) from rats, mice, or humans have also been used for in vitro testing. ${ }^{14,15}$ Advances in liquid handling and culture techniques have improved the usability of primary rat neurons in high-content screening for testing small molecule protein kinase inhibitors., ${ }^{8,9}$ Techniques for generating embryonic stem cell-derived neurons have also been developed, and these cells have been used in automated high-content imaging-based assays monitoring cell viability and neurite outgrowth. ${ }^{7}$

Recently, induced pluripotent stem cell (iPSC)-derived neurons were established and used in functional screening assays for neurite formation and mitochondrial activity. ${ }^{16}$ Human neuronal cells derived from iPSCs are attractive models for toxicity screening because they exhibit the function and behavior of mature neurons and are also available in large quantities sufficient for screening. ${ }^{17,18} \mathrm{Im}$ portantly, human iPSC-derived cells can be established from different individuals to enable disease- and genotype-specific studies. ${ }^{19}$ In vitro studies with iPSC-derived neurons demonstrated in vivo-like electrophysiology, Tau protein secretion, and sensitivity to the potent neurotoxin botulinum. ${ }^{20-22}$ In addition, a number of other iPSCderived cell types have been used successfully for high-content and high-throughput toxicity testing. ${ }^{23-25}$

Taking advantage of both iPSC-derived neurons as a cell model, and high-content imaging as a technique that provides data-rich 
phenotypic readouts, we developed and optimized fast, accurate, and reproducible methods to investigate the viability and morphology of human iPSC-derived neuronal cultures. Specifically, the optimized cell culture protocols allow for maintaining neurons and obtaining reproducible data in a 384-well format. In addition, the improved assay workflow optimizes cell processing through one-step staining, thereby minimizing the disruption of neuronal cultures. We applied these new methods to test select compounds that are known toxicants and report that our assays provide results consistent with the known adverse effects of chemicals on neuronal cells. Finally, by taking advantage of high-content image acquisition through a large field of view camera using single-site acquisition coupled with an improved image analysis software, the analysis results can be reported in real time creating a streamlined protocol for screening environments.

\section{METHODS}

\section{Cell Model}

We used iCell Neurons (Cellular Dynamics International, Madison, WI), human iPSC-derived neurons, for all studies detailed in this report. Characterization of the cells included morphological and immunostaining analyses. ${ }^{26}$ Human iPSC can be developed from adult tissue and blood cells through noninvasive methods, expanded indefinitely, and differentiated into multiple cell types. ${ }^{17,27}$ iCell Neurons used in these studies were provided by the manufacturer as a fully differentiated and highly pure population of cells that formed neurite networks positive for the neuronal markers $\beta$-III tubulin and MAP2. Purity was assessed by counterstaining for iPSC markers; typically less than $1 \%$ of cells were found positive for iPSC markers (data not shown). A similar process for creating such cells has been described previously. ${ }^{18}$

Cryopreserved cells were thawed and plated according to the protocol provided by the Cellular Dynamics International. Briefly, cells were plated on poly-D-lysine precoated 384-well BD Biocoat plates (BD Biosciences, San Jose, CA) that were additionally treated with laminin ( $3.3 \mu \mathrm{g} / \mathrm{mL}$; Sigma-Aldrich, St. Louis, MO). Cells were plated at densities of 2,000-7,000 cells/well in 384-well plates in the iCell Neurons Maintenance Medium (Cellular Dynamics International) at $37^{\circ} \mathrm{C}$ and $5 \% \mathrm{CO}_{2}$. Media were changed every $48 \mathrm{~h}$ until the day of the assay.

\section{Chemicals and Treatments}

For compound screening, stock concentrations of the test agents were prepared as $100 \mathrm{mM}$ stock solutions in tissue culture-grade dimethyl sulfoxide (DMSO). The following test chemical agents (with the highest of the concentration range tested indicated in parentheses) were used in these studies: mitomycin $\mathrm{C}(100 \mu \mathrm{M})$, rotenone $(100 \mu \mathrm{M})$, methylmercury $(100 \mu \mathrm{M})$, retinoic acid $(500 \mu \mathrm{M})$, rapamycin $(100 \mu \mathrm{M})$, and carbonyl cyanide m-chlorophenyl hydrazine (CCCP, $130 \mu \mathrm{M})$. For chemical test wells with final compound concentrations of $\leq 100 \mu \mathrm{M}$, DMSO was present at $0.1 \%$ (vol/vol). For higher compound concentrations, the final DMSO concentration was $\leq 0.3 \%$. Compounds were tested in quadruplicate in an eight-point dilution series. All chemicals were purchased from Sigma-Aldrich. For neurite outgrowth assays, iPSC-derived neurons were cultured for $48 \mathrm{~h}$ before the initiation of the experiment to ensure formation of uniform networks of neurites. Cells were then exposed to the indicated concentrations of compounds for $72 \mathrm{~h}$. For the mitochondrial toxicity assay, cells were cultured for 6-8 days and then exposed to compounds for $30 \mathrm{~min}$.

\section{Multiparametric Live-Cell Toxicity Assay}

Following incubation of the cells with test compounds, media was removed and cells were incubated with a mixture of $1 \mu \mathrm{M}$ Calcein AM and $2 \mu \mathrm{g} / \mathrm{mL}$ Hoechst 33342 in sterile phosphate buffered saline (PBS; all from Life Technologies, Grand Island, NY). The Calcein AM signal was used to measure neurite outgrowth, cell viability, and a variety of morphology parameters. Hoechst 33342 was utilized to measure total cell count and nuclear shape. After a 30 min incubation, the staining solution was replaced with PBS containing $0.1 \%$ of Fetal Bovine Serum (FBS; Life Technologies) and images were acquired using the ImageXpress ${ }^{\circledR}$ Micro XLS (Molecular Devices, Sunnyvale, CA).

\section{Immunostaining iCell Neurons for Neuronal Markers}

Cell culture medium was removed and cells were fixed in $4 \%$ methanol-free dimethyl formaldehyde (Sigma-Aldrich) in PBS for $1 \mathrm{~h}$ at room temperature. Fixed cells were then washed once with PBS, and once with a permeabilization solution (0.02\% saponin [SigmaAldrich] and 2\% FBS in PBS). After the last wash, cells were incubated in permeabilization solution for $1 \mathrm{~h}$ at room temperature. After permeabilization, the cells were stained with AlexaFluor-488conjugated anti- $\beta$-III tubulin (BD Biosciences) 1:20 dilution, or AlexaFluor-633-conjugated anti-MAP2 (BD Biosciences) 1:20 dilution, and $2 \mu \mathrm{M}$ Hoechst 33342, overnight at room temperature. Cells were washed once with PBS before images were acquired. It should be noted that fixing the cells and $\beta$-III tubulin or MAP2 staining can be performed following live cell imaging with Calcein AM (detailed above). This allows for sequential evaluation of several additional neuronal markers. Fixed cells may be also stored for subsequent analyses.

\section{Mitochondrial Membrane Potential Assay}

The mitochondrial membrane potential assay kit (Cell Meter JC10 Mitochondrion Membrane Potential Assay Kit Optimized for Flow Cytometry Assays; AAT Bioquest, Sunnyvale, CA) specifically evaluates a compound's ability to rapidly disrupt the polarity of the mitochondrial membrane. Cells were treated with compounds for $30 \mathrm{~min}$ and the mitochondria dye JC-10 reagent was added. The JC10 reagent in the kit buffer may be added directly to cells after the media with chemical test compounds have been removed. Alternatively, $2 \times$ concentration of the JC- 10 reagent in the kit buffer may be added directly to the media. After $30 \mathrm{~min}$ of the JC-10 staining at $37^{\circ} \mathrm{C}$ and $5 \% \mathrm{CO}_{2}$, images were acquired using the ImageXpress Micro XLS system.

\section{Image Acquisition and Analysis}

Images were acquired using the ImageXpress Micro XLS system using $20 \times$ Plan Fluor ELWD (NA=0.45) or $10 \times$ Plan Fluor $(\mathrm{NA}=0.3)$ 


\section{SIRENKO ET AL.}

objective. The light source was a solid state white light engine with emission from $380 \mathrm{~nm}$ to $680 \mathrm{~nm}$. A FITC filter cube [Ex 482/35, Em 536/40; center wavelength $(\mathrm{nm}) /$ bandpass width $(\mathrm{nm})]$ was used for Calcein AM. A DAPI filter cube (Ex 377/50, Em 447/60) was used for Hoechst 33342.

Images for the mitochondrial permeability assay were acquired using the TRITC and FITC channels for the JC-10 staining along with a DAPI channel if the Hoechst 33342 staining was included. For higher throughput with the multiparametric toxicity assays, one image per well was taken for 384-well plates using a $10 \times$ objective. Images acquired with a $20 \times$ objective allowed higher resolution, better visualization, and improved analysis of the mitochondria.

Images were analyzed using the MetaXpress ${ }^{\circledR} 5$ software (Molecular Devices) Granularity and Neurite Outgrowth modules with or without single cell segmentation based on the optional nuclear staining. Statistical analysis of the data included calculation of a Z'-factor coefficient. As used in this study, it represents the separation of positive or high concentration and negative control wells on a given plate. Typically, eight control wells each for positive and negative controls were included on each plate and $Z^{\prime}$-factor was calculated using the following formula: $Z^{\prime}=1-\left[\left(3^{*} \sigma_{\text {pos }}+3^{*} \sigma_{\text {neg }}\right) /\right.$ $\left.\left|\left(\mathrm{M}_{\text {pos }}-\mathrm{M}_{\text {neg }}\right)\right|\right]$, where $\sigma=$ standard deviation and $\mathrm{M}=$ average value. $\mathrm{EC}_{50}$ values were determined using the 4-parameter curve fit from the SoftMax ${ }^{\circledR}$ Pro software (Molecular Devices).

\section{RESULTS}

Development and Optimization of the Live-Cell High-Content Assay with iPSC-Derived Neurons

The primary goal of this study was to develop and evaluate fast, accurate, and reproducible high-content and high-throughput methods to investigate effects of test compounds on the morphology and viability of iPSC-derived neurons using live and fixed cells. During development, neurons become assembled into functional networks by extending the outward growth of axons and dendrites (collectively called neurites) that connect synaptically to other neurons. Traditional markers that are widely used in in vitro studies of neuronal cell viability and neurite outgrowth are $\beta$-III tubulin and microtubule-associated protein 2 (MAP2). Class III $\beta$-tubulin, or $\beta$-III tubulin, is a microtubule element of the tubulin family found almost exclusively in neurons. ${ }^{28,29}$ Monoclonal antibodies against $\beta$-III tubulin are traditionally used to identify neurons in samples of brain tissue or primary preps of neurons, separating neurons from glial cells. MAP2 belongs to the microtubuleassociated protein family and is thought to be involved in microtubule assembly, which is an essential step in neurogenesis. MAP2 serves to stabilize microtubule growth by crosslinking of microtubules with each other and other intermediate filaments. ${ }^{28,29}$ While $\beta$-III tubulin and MAP2 provide neuronal cell specificity to the in vitro assay readouts, these assays are time consuming, lowerthroughput, and involve multiple steps, including cell fixation, permeabilization, blocking, antibody incubations, and washing. Each of these steps has the potential to disrupt the neuronal cells and introduce variability. Therefore, we tested whether Calcein AM, a homogeneous cell-permeant dye that can be used to determine cell viability in most eukaryotic cells, alone, or in combination with a nuclear stain (e.g., Hoechst 33342), would streamline data acquisition and analysis (Fig. 1).
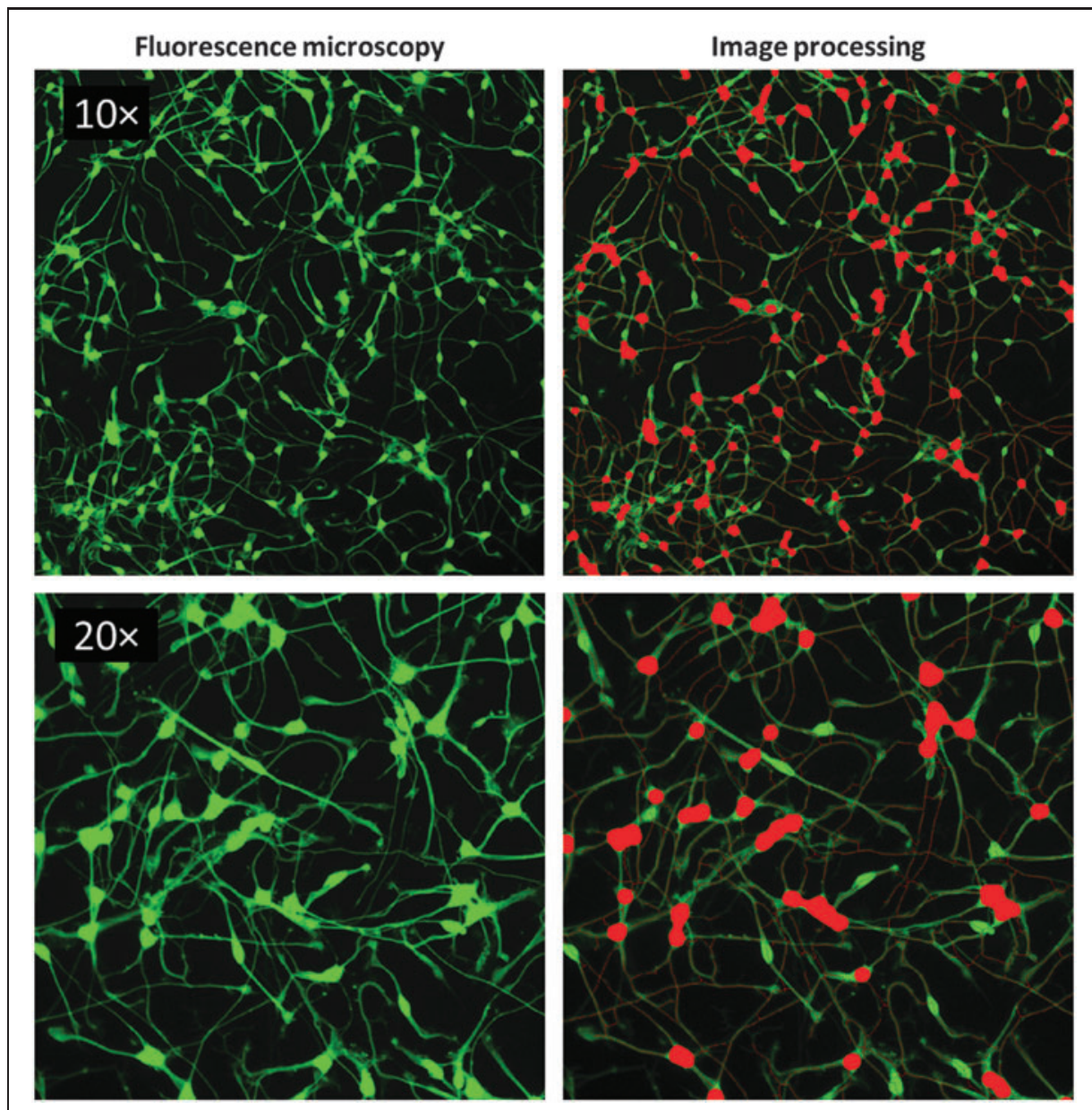

Fig. 1. iCell Neurons were cultured in 384-well plates for 5 days at a density of 7,000 cells/ well and visualized live with Calcein AM. Left panel shows representative fluorescence microscopy images using either $10 \times$ (top row), or $20 \times$ (bottom row) objectives. Right panel shows the outcome of the automated identification of the neuronal bodies (red dots) and outgrowth (thin red lines) using the Neurite Outgrowth module in the MetaXpress 5 software. 
The assay was optimized for iPSC-derived neuronal cells (iCell Neurons) that represent a highly homogeneous population of neuronal cells. Calcein AM was used as a marker for both cell viability (percent of live cells) and neurite outgrowth. A key benefit of using this dye in the assay is that neuronal bodies and processes can be visualized simultaneously in live cells as indicated by the $10 \times$ and $20 \times$ images presented in Figure 1. In experiments with Calcein AM dye, images of the individual wells were acquired with the ImageXpress Micro XLS system using $10 \times$ or $20 \times$ objectives (Fig. 1). Typically, one $10 \times$ or four $20 \times$ images are captured per well in a 384-well plate. A $10 \times$ objective provides sufficient resolution to distinguish neurite networks and sub-cellular structures in a relatively large number of cells $(500-1,000)$ per image, which represents about $1 / 4$ of the total well area. Use of a $20 \times$ objective decreases the number of cells (120-200) captured in a single image, but may improve detection of finer neurite branches and processes. Neuronal bodies typically exhibited fluorescence intensities $>10$ times brighter than neurite outgrowths (Table 1), thus allowing for efficient distinction between those cellular components during image processing and indicated by the red masks shown in Figure 1. As expected, we observed efficient formation of neurite outgrowth networks in iCell Neurons cultured in 384-well plates, and images were easy to acquire and process through an automated image analysis procedure that

\section{Table 1. Optimization of Calcein AM Staining \\ for iCell Neurons Assays \\ Neurite outgrowth intensity Total neurite outgrowth, $\mu \mathrm{m}$

\begin{tabular}{|l|c|c|c}
\hline Average \pm SD & CV (\%) & Average \pm SD & CV (\%)
\end{tabular}

Time of incubation, min (with $1 \mu \mathrm{M}$ Calcein AM)

\begin{tabular}{c|c|c|c|c}
\hline 5 & $596 \pm 83$ & 14 & $96,400 \pm 10,300$ & 11 \\
\hline 15 & $1,002 \pm 36$ & 3.6 & $189,800 \pm 8,700$ & 4.6 \\
\hline 30 & $1,810 \pm 110$ & 6.1 & $216,100 \pm 5,300$ & 2.5 \\
\hline 60 & $2,350 \pm 110$ & 4.6 & $226,300 \pm 8,600$ & 3.9 \\
\hline 120 & $2,543 \pm 74$ & 2.9 & $204,200 \pm 7,400$ & 3.6 \\
\hline 180 & $2,650 \pm 120$ & 4.5 & $124,800 \pm 9,100$ & 7.3 \\
\hline
\end{tabular}

Calcein AM concentration, $\mu \mathrm{M}$ (at 30 min incubation)

\begin{tabular}{c|c|c|c|c}
\hline 3 & $3,130 \pm 280$ & 8.9 & $212,500 \pm 3,400$ & 1.6 \\
\hline 2 & $2,560 \pm 150$ & 5.9 & $222,600 \pm 2,300$ & 1.0 \\
\hline 1 & $1,640 \pm 140$ & 8.5 & $200,100 \pm 1,700$ & 0.8 \\
\hline 0.3 & $870 \pm 270$ & 31 & $154,900 \pm 1,600$ & 1.0 \\
\hline 0.1 & $360 \pm 120$ & 33 & $1,790 \pm 410$ & 23 \\
\hline
\end{tabular}

Results were calculated using one image per well in a 384-well plate using a $10 \times$ objective. Cells were stained as described in the text. Averages were derived from three wells on the same plate. provided quantitative data, including the average fluorescent intensities and the total outgrowth/length $(\mu \mathrm{m})$ of the detected neurites (Fig. 1 and Table 1). An initial $1 \mu \mathrm{M}$ concentration of Calcein AM was selected based on recommendations from the manufacturer and proved to give good signal-to-background discrimination during imaging with a short 10-20 ms exposure. In addition, a dilution series of Calcein AM was performed and an acceptable concentration range was found between $0.3 \mu \mathrm{M}$ and $3 \mu \mathrm{M}$ (Table 1). A time course of Calcein AM staining from $15 \mathrm{~min}$ to $3 \mathrm{~h}$ was also performed to optimize experimental conditions. Neuronal fluorescence intensity reached about $80 \%$ of the maximal value by $30 \mathrm{~min}$ and stabilized after $1 \mathrm{~h}$ incubation with Calcein AM (Table 1). The extent of neurite outgrowth was found to diminish after $3 \mathrm{~h}$ incubation with the dye (Table 1). Based on these data a $1 \mu \mathrm{M}$ concentration of Calcein AM with a staining time of 30 min was selected for all further assays. To test the effect of cell plating density on assay variability in 384-well plates, we plated iCell Neurons at three different densities $(2,000-$ 7,000 per well), cultured them for $48 \mathrm{~h}$, and then exposed the cells to $0.1 \%$ DMSO for $72 \mathrm{~h}$. On day 5, cells were stained with Calcein AM and analyzed. It was found that 7,000 cells per well plating density resulted in the lowest variability in the measured parameters between wells (Table 2).

Quantitative analysis of the images captured in these experiments included the derivation of multiple parameters that allow for the assessment of both the morphological features of cultured neurons, and the extent and degree of complexity of the neuronal networks (Table 3). Specifically, neurite outgrowth was characterized by the extent of the outgrowth (e.g., the number and percent of cells with significant outgrowth, length of total outgrowth, and mean outgrowth per cell), the number of neurite processes (e.g., total number of processes and mean number of processes per cell), and the extent of branching (e.g., total number of branches and mean number of branches per cell). Neurite outgrowth was determined by the length of the skeletonized outgrowth in each image, corrected for the diagonal length. Processes were classified as primary neurites originating from the cell body. Branches were determined as neurites

Table 2. Comparison of Plating Density on iCell Neurons Viability and Neurite Outgrowth

\begin{tabular}{|c|c|c|c|c|}
\hline \multirow{2}{*}{$\begin{array}{l}\text { Plating density } \\
\text { (cells/well) }\end{array}$} & \multicolumn{2}{|c|}{ Viable cell number } & \multicolumn{2}{|c|}{ Total neurite outgrowth, $\mu \mathrm{m}$} \\
\hline & Average \pm SD & CV $(\%)$ & Average \pm SD & CV $(\%)$ \\
\hline 7,000 & $698 \pm 19$ & 2.7 & $144,400 \pm 5,800$ & 4.0 \\
\hline 4,000 & $326 \pm 52$ & 16 & $72,500 \pm 6,200$ & 8.6 \\
\hline 2,000 & $169 \pm 35$ & 21 & $51,500 \pm 9,300$ & 18 \\
\hline
\end{tabular}

Results were calculated using one image per well in a 384-well plate using a $10 \times$ objective. Cells were cultured for $48 \mathrm{~h}$ without treatment and then for $72 \mathrm{~h}$ in the presence of $0.1 \%$ DMSO. Averages were derived from 16 wells on the same plate. 
Table 3. Comparison of Imaging Resolution with $10 \times$ and $20 \times$ Objectives on the Reproducibility of Retinoic Acid-Induced Changes in the Phenotypic Parameters in iCell Neurons

\begin{tabular}{|c|c|c|c|c|}
\hline \multirow[b]{2}{*}{ Parameter } & \multicolumn{2}{|c|}{$20 \times$ Objective 1 Site/well } & \multicolumn{2}{|c|}{$20 \times$ Objective 4 Sites/well } \\
\hline & Vehicle & Retinoic acid & Vehicle & Retinoic acid \\
\hline Number of cells per image & $500 \pm 27$ & $13 \pm 12$ & $130 \pm 5$ & $6.8 \pm 4.1$ \\
\hline Cells with significant outgrowth & $478 \pm 27$ & $0.5 \pm 0.6$ & $127 \pm 5$ & $0.4 \pm 0.5$ \\
\hline$\%$ Cells with significant outgrowth & $95.5 \pm 1.5$ & $2.4 \pm 3.0$ & $97.3 \pm 1.0$ & $3.9 \pm 3.0$ \\
\hline Total outgrowth, $\mu \mathrm{m}$ & $93,800 \pm 2,900$ & $36 \pm 50$ & $35,800 \pm 500$ & $43 \pm 26$ \\
\hline Mean outgrowth per cell, $\mu \mathrm{m}$ & $188 \pm 10$ & $2 \pm 2$ & $276 \pm 12$ & $5.4 \pm 2.6$ \\
\hline Total number of processes & $1,949 \pm 91$ & $6 \pm 8$ & $684 \pm 40$ & $5.3 \pm 3.1$ \\
\hline Mean number of processes per cell & $3.90 \pm 0.07$ & $0.3 \pm 0.2$ & $5.2 \pm 0.1$ & $0.7 \pm 0.1$ \\
\hline Total number of branches & $2,640 \pm 140$ & $0 \pm 0$ & $1,780 \pm 46$ & $0.3 \pm 0.5$ \\
\hline Mean number of branches per cell & $5.3 \pm 0.4$ & $0 \pm 0$ & $13.7 \pm 0.7$ & $0.3 \pm 0.7$ \\
\hline Acquisition Time for 384-well plate & $17 \mathrm{~min}$ & & $68 \min$ & \\
\hline
\end{tabular}

Results (average \pm SD) were calculated using one image per well using a $10 \times$ objective or four images per well using a $20 \times$ objective in a 384-well plate. Cells were cultured at 7,000/well for $48 \mathrm{~h}$ without treatment and then for $72 \mathrm{~h}$ in the presence of vehicle (0.1\% DMSO) or $200 \mu \mathrm{M}$ retinoic acid. Averages and SD's were derived from 16 wells on the same plate. Values are given on a per site basis.

originating from a primary neuron. Other parameters that may be captured include: process fluorescent intensity, neuronal body area, and significant growth (neurites that have outgrowth greater than a selected length, e.g., $25 \mu \mathrm{m})$.

Because $10 \times$ imaging considerably reduces the amount of time needed to acquire the entire 384-well plate, we performed a comparison of the variability in the parameters captured with different objectives. iCell Neurons were cultured in the presence of vehicle (0.1\% DMSO) or retinoic acid $(200 \mu \mathrm{M})$ for $72 \mathrm{~h}$, and live cell imaging was performed with different objectives. Retinoic acid is associated with developmental neuronal toxicity and produced representative phenotypic changes in neurite outgrowth. ${ }^{12,30}$ We found that both $10 \times$ and $20 \times$ imaging modes yield highly reproducible data and similar results (Table 3); however, the acquisition time was only $17 \mathrm{~min}$ for the entire 384 -well plate when a $10 \times$ objective and one image per well settings were used, as compared with $68 \mathrm{~min}$ when a $20 \times$ objective was used to acquire four images per well. During image acquisition plates were kept at $37^{\circ} \mathrm{C}$. Cells may be imaged directly without washing steps, or staining solution may be removed and substituted with PBS or another physiological buffer. In addition, $0.1 \%$ FBS can be added to PBS to support cell viability if multiple plates are to be processed simultaneously. Plates may be fixed and stored, but must be restained with an antibody-based stain (for example anti- $\beta$-III-tubulin or MAP2 antibodies) to be fluorescently imaged because Calcein AM is fluorescent only in live cells.
These results indicate that the assay is suitable for multiparametric analysis and provides the ability to quantify different biological outputs. To determine whether live cell imaging of Calcein AM stained iCell Neurons is amenable to high-content imaging-based concentration-response profiling of the effects of chemicals on neuronal cell cultures, we treated cells with selected compounds. Those include methylmercury (MeHg), a ubiquitous environmental toxicant that leads to longlasting neurological and developmental deficits in animals and humans; ${ }^{31}$ rotenone, a pesticide known to induce neurotoxicity $;^{32,33}$ mitomycin C, an anticancer drug (alkylating agent), known to cause neuropathies; ${ }^{34}$ and retinoic acid, at high doses is a known developmental neurotoxicant. ${ }^{30}$ Representative images of Calcein AM stained iCell Neurons treated with increasing concentrations of these compounds are shown in Figure 2. A concentration-dependent disintegration of the neuronal networks and a loss of cell viability were observed with all four compounds (Tables 4 and 5). Even though a clear concentration-response was observed in all parameters with each test compound, we found that the parameters that represent total outgrowth or branching of neurons in culture were most sensitive indicators of toxicity as compared to cytotoxicity parameters (e.g., number of viable cells). For example, methylmercury induced disintegration of networks at lower concentrations than it affected cell viability: $\mathrm{EC}_{50}$ values for neurite outgrowth were $<1 \mu \mathrm{M}$, whereas values for cell viability were $>6 \mu \mathrm{M}$. In contrast, for mitomycin $\mathrm{C}$ the $\mathrm{EC}_{50}$ values for different parameters were comparable. Thus, one use of multiparametric high-throughput assayderived information may be for separating chemicals into either those that cause toxicity primarily through nonselective interactions with cells and cellular macromolecules or those that act through more selective interactions (e.g., disruption of neuronal branching).

\section{Comparison of the Calcein AM Assay to $\beta$-III Tubulin and MAP2 Assays for Cultured iCell Neurons}

In addition to live cell imaging with Calcein AM as detailed above, we also performed a direct comparison of Calcein AM, $\beta$-III tubulin, and MAP2 staining in iCell Neurons. First, iCell Neurons were plated, cultured in the presence or absence of the chemical compounds, and imaged as live cells using Calcein AM. Immediately thereafter, cells were fixed, washed, and permeabilized to enable antibody-enabled staining. Cells were stained with conjugated antibodies for $\beta$-III tubulin and MAP2 with or without additional nuclear counter stain. Comparing the two techniques, Calcein AM 


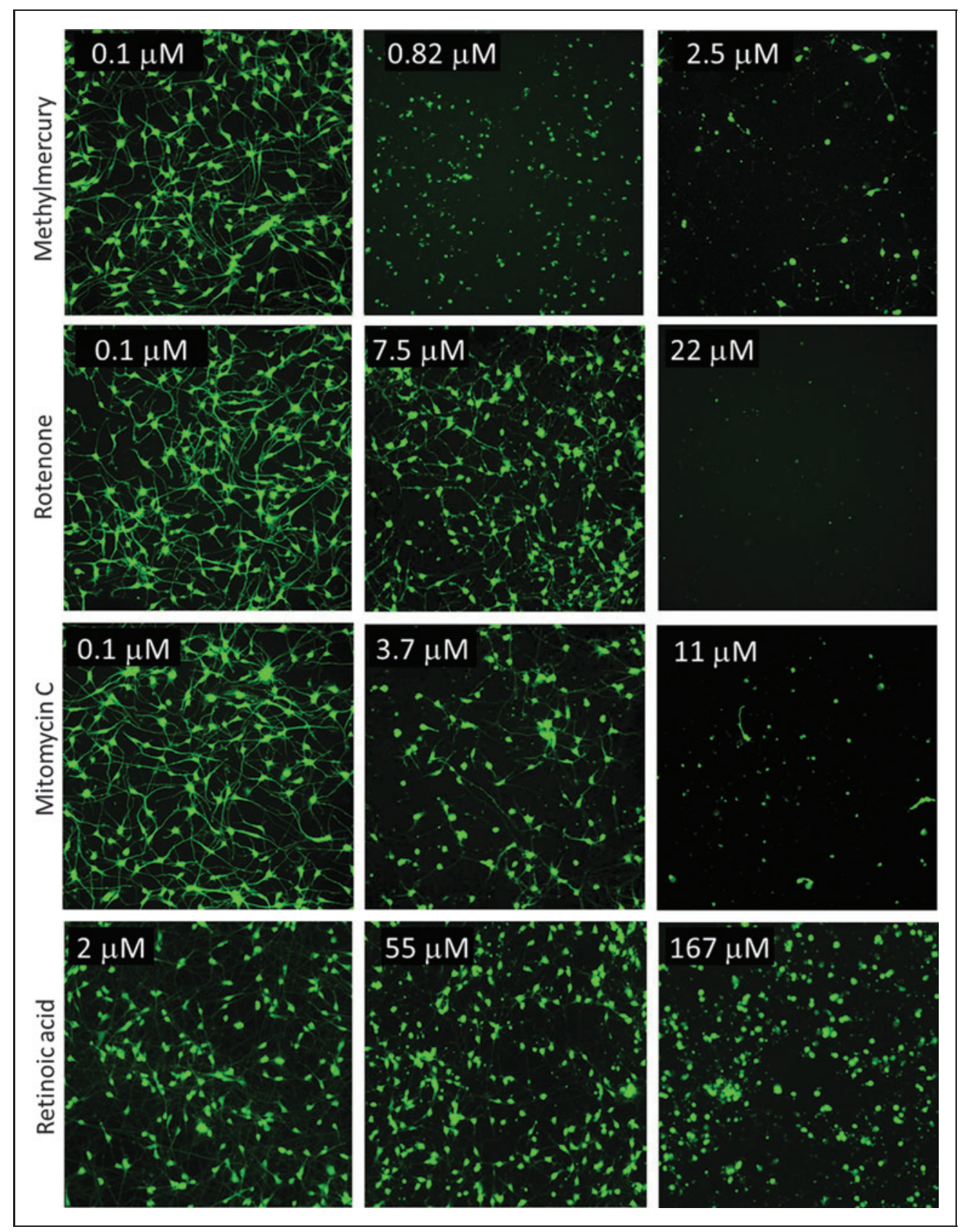

Fig. 2. Concentration-response effects of select toxicants on iCell Neurons using Calcein AM livecell assay. iCell Neurons were incubated with indicated compounds for $72 \mathrm{~h}$ and stained with Calcein AM. Cells were imaged on the ImageXpress Micro XL system using $10 \times$ objective. Concentrations are shown on each image.

involves a one-step staining process with 30 min incubation whereas antibody staining requires multiple steps to fix, permeabilize, and wash the cells followed by an overnight incubation. The antibody concentrations were set to those recommended in the manufacturer's protocol for staining of primary neurons; thus, the impact of different antibody concentrations or timing on image quality was not evaluated in studies detailed herein. We note that excellent image quality was obtained using the manufacturer's recommended conditions (Fig. 3). Cells were visualized using the FITC channel for $\beta$-III tubulin $(\sim 100 \mathrm{~ms}$ exposure), the Сy5 channel for MAP2 ( 200 ms exposure), and the DAPI channel for the nuclear stain ( $\sim 100 \mathrm{~ms}$ exposure). Image analysis was performed using the Neurite Outgrowth module in the MetaXpress 5 software to identify the neuronal bodies using the nuclear stain, and then characterize $\beta$-III tubulin- or MAP2-labeled neurite outgrowth (Supplementary Table S1; Supplementary Data are available online at www.liebertpub.com/adt). Optimization of the image analysis module and the parameter sets that provided good performance were similar to those described for the Calcein AM live-cell assay.

We evaluated different output parameters using selected compounds described previously and quantified their effects on the extent and morphology of neurite networks (Fig. 4 and Tables 5 and 6). The concentration-dependent effects of test compounds on the images and data obtained with all three staining methods were found to be both visually (Fig. 4) and quantitatively (Fig. 5) very similar. While the concentration-dependent toxicity phenotypes collected in this study (reported for the total outgrowth phenotype in Table 6) were comparable between Calcein AM and $\beta$-III tubulin assays, the values for neurite outgrowth phenotypes were $20 \%-40 \%$ smaller in the MAP2 assay and statistically different from the other two methods for most compounds (Supplementary Table S1). A possible reason for this result is that the neurites do not equally coexpress both $\beta$-III tubulin and MAP2 markers. Similar to the compound $\mathrm{EC}_{50}$ values, the assay performance metrics (coefficient of variation) for the selected compounds were also very close and had a similar rank order for both Calcein AM and $\beta$-III tubulin assays; however, the MAP2 assay exhibited higher variability (Supplementary Table S1). 


\begin{tabular}{|c|c|c|c|c|}
\hline \multirow[b]{2}{*}{ Parameter } & $\begin{array}{l}\text { Methylmercury } \\
(0-100 \mu \mathrm{M})\end{array}$ & $\begin{array}{c}\text { Mitomycin C } \\
(0-100 \mu \mathrm{M})\end{array}$ & $\begin{array}{c}\text { Rotenone } \\
(0-100 \mu \mathrm{M})\end{array}$ & $\begin{array}{c}\text { Retinoic acid } \\
(0-500 \mu \mathrm{M})\end{array}$ \\
\hline & \multicolumn{4}{|c|}{$\mathrm{EC}_{50} \pm \mathrm{SD}(\mu \mathrm{M})$} \\
\hline Number of cells with significant outgrowth & $0.99 \pm 0.05$ & $9.7 \pm 1.6$ & $3.8 \pm 0.2$ & N.A. \\
\hline$\%$ Of cells with significant outgrowth & $1.3 \pm 0.2$ & $30 \pm 1$ & N.A. & N.A. \\
\hline Total outgrowth, $\mu \mathrm{m}$ & $0.61 \pm 0.02$ & $9.1 \pm 0.8$ & $2.7 \pm 0.2$ & $39 \pm 2$ \\
\hline Mean outgrowth per cell, $\mu \mathrm{m}$ & $0.57 \pm 0.07$ & $15 \pm 3$ & $2.8 \pm 0.6$ & $34 \pm 5$ \\
\hline Total number of processes & $0.87 \pm 0.01$ & $8 \pm 2$ & $3.2 \pm 0.1$ & $54 \pm 1$ \\
\hline Mean number of processes per cell & $0.94 \pm 0.41$ & $11.9 \pm 0.9$ & $3.5 \pm 0.3$ & $48 \pm 5$ \\
\hline Total number of branches & $0.42 \pm 0.03$ & $7.4 \pm 1.3$ & $2.0 \pm 0.3$ & $27 \pm 3$ \\
\hline Mean number of branches per cell & $0.41 \pm 0.05$ & $8.9 \pm 1.3$ & $2.0 \pm 0.3$ & $24 \pm 4$ \\
\hline Number of viable cells & $6.2 \pm 1.2$ & $11 \pm 2$ & $4.9 \pm 0.4$ & N.A. \\
\hline
\end{tabular}

Results were calculated using one image per well in a 384-well plate using a 10× objective. Cells were cultured at 7,000/well for $48 \mathrm{~h}$ without treatment and then for $72 \mathrm{~h}$ in the presence of increasing concentrations of the compounds in DMSO vehicle. $\mathrm{EC}_{50}$ values were derived using the 4-parametric curve fit. N.A. means no fit was obtained to the data. Four replicates were taken at each concentration and compounds were run over three representative experiments.

Development and Optimization of the Mitochondrial Potential Assay for Cultured iCell Neurons

For additional in-depth investigation into the potential cytotoxic mechanisms elicited by different test compounds on iCell Neurons, we also evaluated the mitochondrial depolarization phenotype. We monitored the mitochondrial membrane potential using short-time compound treatment (30 min) protocols with the mitochondria active dye JC-10, a derivative of $\mathrm{JC}-1 .{ }^{35}$ In viable cells, JC-10 selectively accumulates in the mitochondria and can be detected as orange J-aggregates. If the inner membrane potential is lost, the monomeric form of JC-10 is released into the cytoplasm and the cells fluoresce green. Typical JC10 staining patterns for control cells, and those treated with the mitochondrial toxicant rotenone, are shown in Figure 6A. JC-10 staining may be also combined with Hoechst nuclear dye to allow efficient segmentation of individual cells. Typical exposure times were 10-15 ms for JC-10 (TRITC channel) and 50-100 ms for Hoechst (DAPI channel). The dye concentration used was that recommended by the manufacturer (1:200 dilution) and the dye was diluted using a JC-10 assay buffer. A dye dilution series was tested and variation of fluorescence intensity with dye concentration was found to be linear (Table 7). The fluorescent signal was found to reach maximum intensity less than $30 \mathrm{~min}$

Table 5. Multiparametric Assessment of the Effects of Compounds on iCell Neurons Using Calcein AM Live-Cell Assay

\begin{tabular}{|c|c|c|c|c|c|}
\hline & Control & $\begin{array}{l}\text { Methylmercury } \\
\qquad(3 \mu \mathrm{M})\end{array}$ & $\begin{array}{c}\text { Mitomycin C } \\
(10 \mu \mathrm{M})\end{array}$ & $\begin{array}{l}\text { Rotenone } \\
(20 \mu \mathrm{M})\end{array}$ & $\begin{array}{c}\text { Retinoic acid } \\
(120 \mu \mathrm{M})\end{array}$ \\
\hline Number of viable cells & $498 \pm 18$ & $72.7 \pm 23.2$ & $118 \pm 24$ & $143 \pm 94$ & $210 \pm 62$ \\
\hline Number of cells with significant outgrowth & $468 \pm 17$ & $0.25 \pm 0.53$ & $0.88 \pm 1.19$ & $0.25 \pm 0.46$ & $0.50 \pm 0.89$ \\
\hline$\%$ Cells with significant outgrowth & $93.9 \pm 1.4$ & $1.40 \pm 3.29$ & $2.59 \pm 3.86$ & $0.11 \pm 5.20$ & $1.9 \pm 3.0$ \\
\hline Total outgrowth, $\mu \mathrm{m}$ & $89,800 \pm 5,200$ & $19 \pm 31$ & $83 \pm 87$ & $203 \pm 185$ & $47 \pm 75$ \\
\hline Mean outgrowth per cell, $\mu \mathrm{m}$ & $184 \pm 12$ & $1.48 \pm 2.08$ & $2.11 \pm 2.91$ & $1.4 \pm 3.0$ & $1.7 \pm 2.4$ \\
\hline Total number of processes & $1,970 \pm 72$ & $2.69 \pm 3.39$ & $10.5 \pm 8.0$ & $1.6 \pm 3.8$ & $6.1 \pm 9.7$ \\
\hline Mean processes per cell & $3.96 \pm 0.15$ & $0.22 \pm 0.22$ & $0.25 \pm 0.39$ & $0.11 \pm 0.63$ & $0.23 \pm 0.33$ \\
\hline Total number of branches & $2,530 \pm 280$ & $59.8 \pm 26.8$ & $4.50 \pm 3.11$ & $11 \pm 2.4$ & $38 \pm 19$ \\
\hline Mean number of branches per cell & $5.08 \pm 0.60$ & $0.82 \pm 0.01$ & $0.04 \pm 0.001$ & $0.08 \pm 0.67$ & $0.18 \pm 0.01$ \\
\hline
\end{tabular}

Results were calculated using one image per well in a 384-well plate using a $10 \times$ objective. Cells were cultured at 7,000/well for $48 \mathrm{~h}$ without treatment and then for $72 \mathrm{~h}$ in the presence of indicated concentrations of the compounds in DMSO vehicle. Averages for positive and negative controls were derived from eight wells on the same plate. 
HIGH-CONTENT SCREENING USING IPSC-DERIVED NEURONS

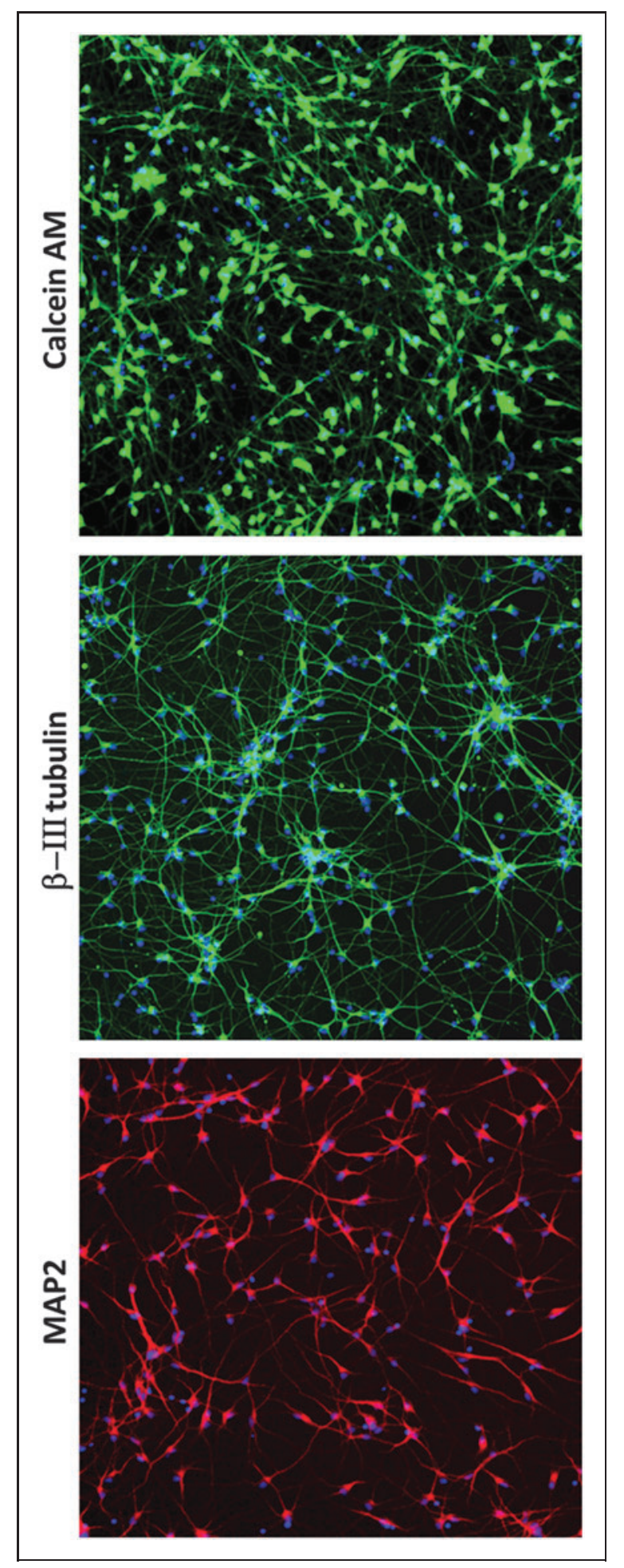

Fig. 3. Comparative analysis of Calcein AM, $\beta$-III tubulin, and MAP2 staining patterns in iCell Neurons. iCell Neurons were cultured in 384-well plates for 5 days at a density of 7,000 cells/well and visualized with Calcein AM (top), $\beta$-III tubulin (middle), and MAP2 (bottom) using $10 \times$ objective. Hoechst nuclear stain (blue) was also used in all wells. poststaining. Cytotoxic effects of JC-10 dye were apparent at dilutions above 1:200 after $2 \mathrm{~h}$ in culture (data not shown).

After the JC-10 staining protocol was optimized as described above, iCell Neurons were exposed to several test compounds for $30 \mathrm{~min}$ and treated with JC-10 for additional $30 \mathrm{~min}$. Furthermore, to avoid any increase in resistance of the cells to the mitochondria damaging agents caused by glucose in the media, glucose-free media (RPMI glucose-free) was used for $30 \mathrm{~min}$ before treatments. Test compounds were diluted in the same glucose-free media. Mitochondria positive for JC-10 accumulation were localized within cell bodies and neurites, and exhibited a granular appearance; therefore, images were analyzed using the Granularity analysis module in the MetaXpress 5 software. The best results were obtained using a $10 \times$ objective (one image per well) or a $20 \times$ objective (one to two images per well). Typical granules were $0.5-4 \mu \mathrm{M}$ diameter. The background threshold was adjusted to allow maximum separation of the positive and negative samples ( $\sim 700-1,500$ gray levels).

Treatment with compounds damaging to mitochondria resulted in a concentration-dependent decline in the JC-10 staining intensity and the number of granules (Fig. 6B). The analysis identifies JC-10 positive granules, and, therefore, reports the number of mitochondria with uncompromised membrane potential. Specifically, we used rotenone, a compound that causes interruption of oxidative respiration and $\mathrm{Ca}^{2+}$ overload, and inhibitors of oxidative phosphorylation, carbonyl cyanide m-chlorophenyl hydrazone (CCCP), and rapamycin. ${ }^{36}$ This assay also enables derivation of multiple parameters from the imaging output. Specifically, the Granularity analysis module enables measurements of chemically induced changes in the granule area in the entire image and individual cells, the number of granules, and the granule intensity (Table 8). In contrast, cell number was not affected during the short-time (30 min) compound exposure.

\section{DISCUSSION}

There is a great need for improved high-throughput methods to measure neuronal toxicity in vitro to evaluate the potential effects of drugs and chemicals, industrial and environmental, on neurons. Recent developments in cell biology have generated novel in vitro models for the evaluation and prioritization of compounds for subsequent in vivo testing, including human iPSC-derived neuronal cells. ${ }^{19}$ We present, in this study, examples of how iCell Neurons can be used to evaluate morphological changes and the extent of neurite outgrowth in high-content imaging assays that are suited for medium-throughput quantitative screening of compounds. The morphology, marker expression, and many functional characteristics of the neurons used in this study are consistent with those identified in primary cells. ${ }^{22}$ In contrast to rat hippocampal neurons and other available primary cell models, iPSC-derived neurons represent human biology, are available in large quantities, stable in culture, and display consistent reproducible phenotypes. ${ }^{17,18}$

High-content imaging of neuronal cells has been demonstrated to be particularly useful for toxicity screening as it can assess subtle phenotypic changes and provide multiparametric readouts. ${ }^{12,37}$ The main outcome from this study is a new straightforward 


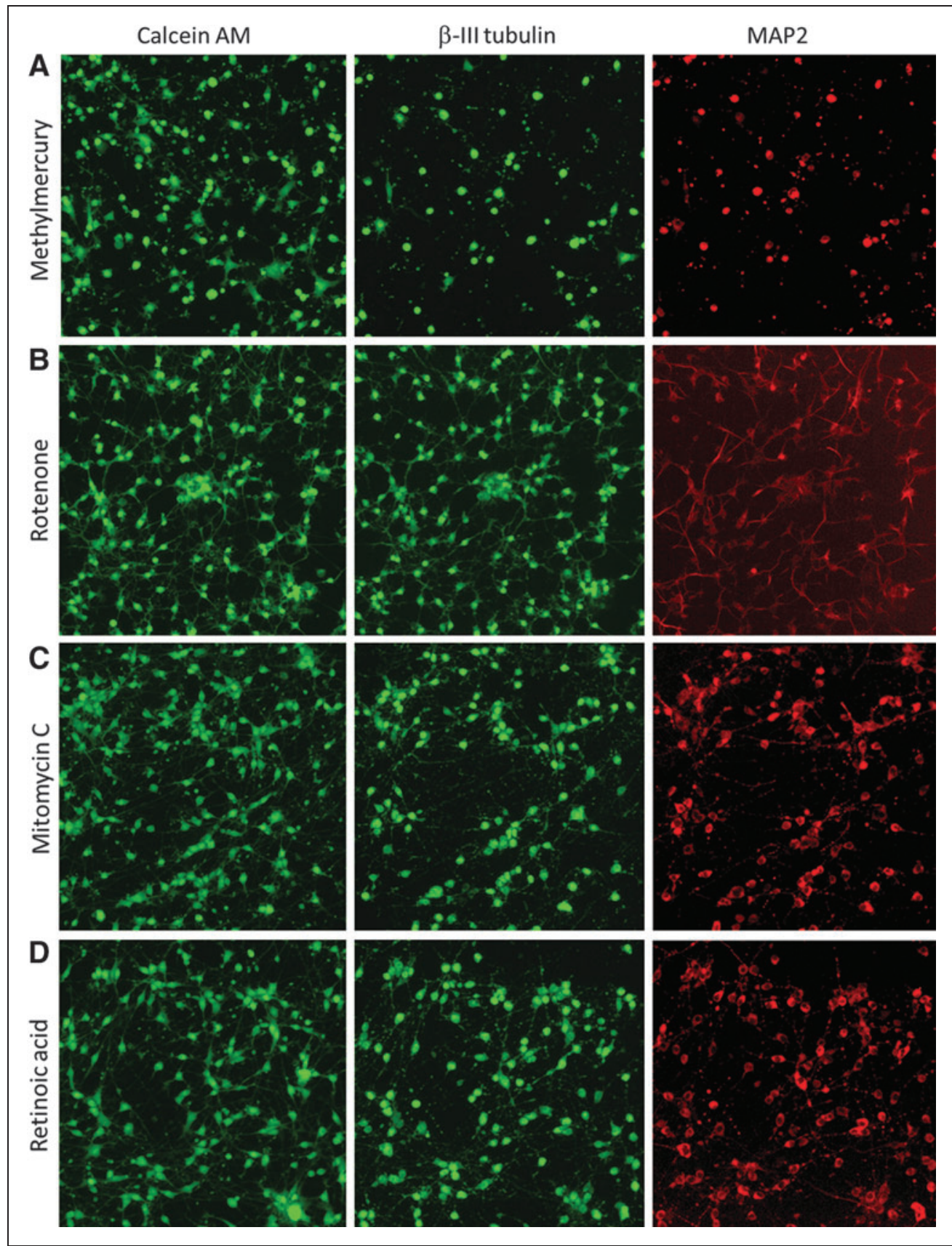

Fig. 4. Comparative analysis of the toxic effects of select chemicals on iCell Neurons using Calcein AM, $\beta$-III tubulin, and MAP2 staining. iCell Neurons were subject to the following treatments: (A) methylmercury $(3 \mu \mathrm{M})$, (B) rotenone $(10 \mu \mathrm{M})$, (C) mitomycin $\mathrm{C}(3 \mu \mathrm{M})$, and (D) retinoic acid (55 $\mu \mathrm{M})$. Cells were imaged on the ImageXpress Micro XLS system using a $10 \times$ objective. Images for each dye series were scaled to the same intensity range.

high-content analysis method based on the commonly used cell viability dye Calcein AM. While it is widely used in other cell-based imaging assays, its application to the iPSC-derived neuronal cells has the potential to both reduce cost and increase throughput of experiments. The homogeneous single-step staining protocol saves time because it is significantly shorter than traditional antibody staining protocols, minimizes the potential disruption to neuronal cultures, and by eliminating multiple automation steps reduces the opportunities to introduce assay variability. The automated multiparametric screening method and optimized protocol for cell treatment, imaging, and image analysis can greatly increase the productivity of chemical safety screening studies. We have demonstrated that the ImageXpress Micro XLS system provides excellent performance and has the ability to capture a large number of cells with sufficient neurite outgrowth definition in a single image per well. Single site and single wavelength channel per well acquisition of high-resolution images in a 384-well format can considerably increase throughput.

Importantly, the image analysis step delivers a number of very informative phenotypic read-outs and output parameters that can be used to screen for deleterious effects of test compounds on cell morphology and viability from a simple workflow assay protocol. Using specific examples and a set of known toxic compounds, we demonstrated how different readouts can be used in combination to characterize adverse effects on neurite outgrowth, branching, mitochondrial potential, and other parameters to assess different types of toxicity. For viability and morphological changes, cells were typically exposed to compounds for $72 \mathrm{~h}$, which is consistent with previous in vitro studies in different cell models. ${ }^{25,38}$

The analysis step generates information that is reflective of the effects in either the total image area or individual cells. If cell plating is not uniform across a well or within an image area, mean per cell values normalized by the total cell number in the image may yield more useful data. Additional phenotypic readouts that can be obtained from the same Calcein AM assay include cell viability and cell area. The number of live and dead neurons can be determined by counting viable neuronal bodies using the Cell Scoring analysis module. Images are first 
Table 6. Comparison of the Concentration-Dependent

Effects of Selected Compounds on the Total Neurite

Outgrowth Phenotypes of iCell Neurons Stained

by Three Distinct Methods

\begin{tabular}{|c|c|c|c|}
\hline & Calcein AM & $\beta$-III tubulin & MAP2 \\
\hline (Concentration range, $\mu \mathrm{M}$ ) & \multicolumn{3}{|c|}{$\mathrm{EC}_{50} \pm \mathrm{SD}(\mu \mathrm{M})$} \\
\hline Methylmercury (0-100) & $0.60 \pm 0.02$ & $0.48 \pm 0.08$ & $0.44 \pm 0.20$ \\
\hline Rotenone (0-100) & $4.1 \pm 0.3$ & $3.9 \pm 0.8$ & $1.7 \pm 0.9$ \\
\hline Mitomycin C (0-100) & $9.1 \pm 0.8$ & $7.2 \pm 0.8$ & $3.9 \pm 0.5$ \\
\hline Retinoic acid (0-300) & $30 \pm 1.5$ & $27 \pm 1.8$ & $28 \pm 12$ \\
\hline
\end{tabular}

Three replicates of each concentration were used to determine $\mathrm{EC}_{50}$ values. Error values were determined from the error of the 4-parameter curve fit at the $50 \%$ effect level.

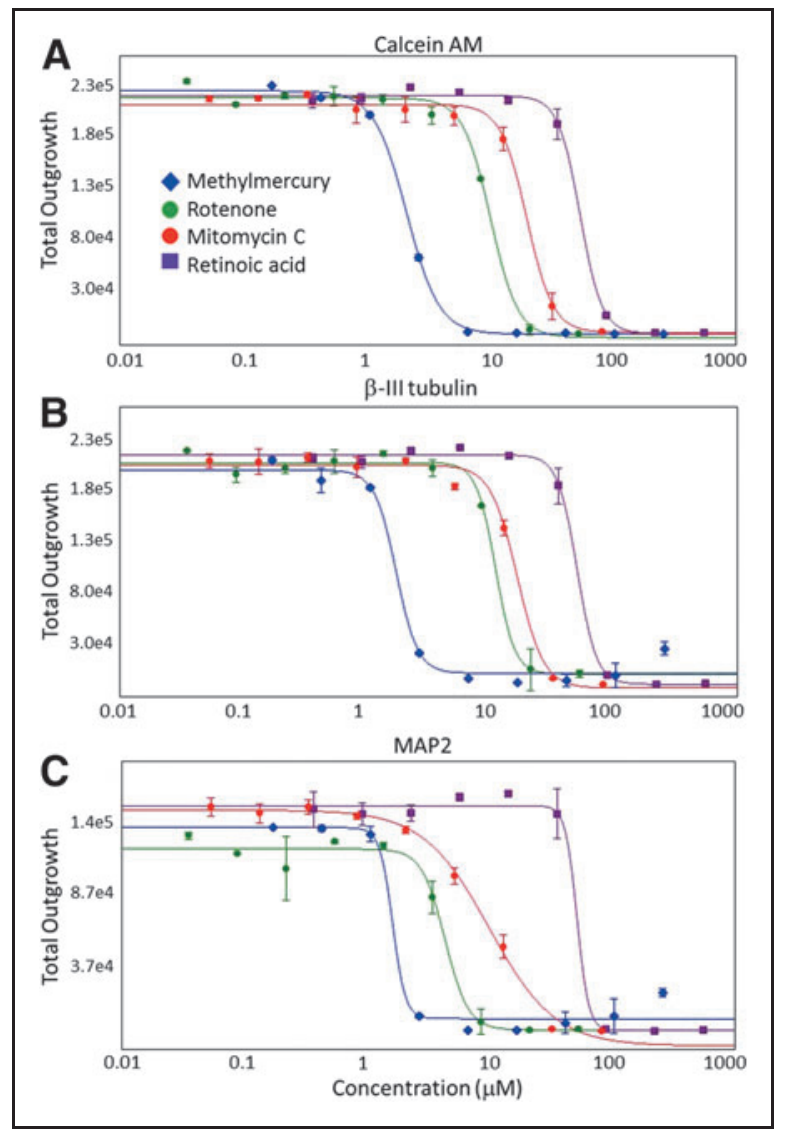

Fig. 5. Comparison of live-cell assay using Calcein AM (A) to fixedcell assays using $\beta$-III tubulin (B) and MAP2 (C). Concentrationresponse curves with the 4-parameter fits are shown with resulting $\mathrm{EC}_{50}$ values given in Table 6. Four replicates were acquired for each data point. Error bars represent \pm 1 SD. Methylmercury (blue diamond), rotenone (green circle), mitomycin C (red circle), retinoic acid (purple square).

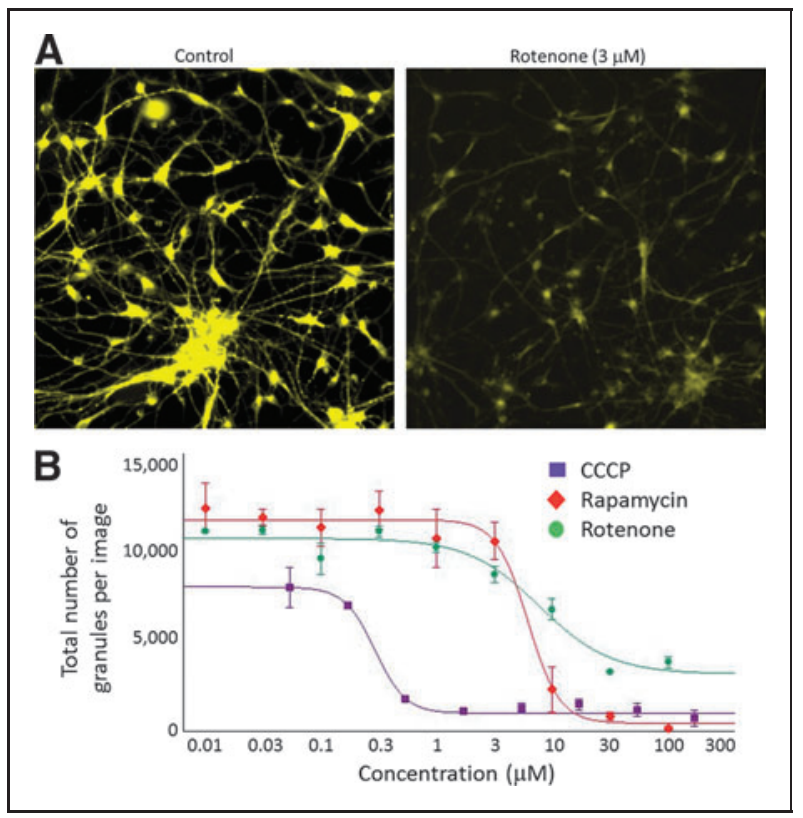

Fig. 6. Analysis of mitochondrial integrity in iCell Neurons using JC10 staining. (A) Images of control (0.1\% DMSO) and treated (rotenone, $7 \mu \mathrm{M}$, $30 \mathrm{~min}$ ) iCell Neurons stained with the JC-10 dye. (B) Concentration-response analysis of the effects ( $30 \mathrm{~min}$ of treatment) of select chemicals [carbonyl cyanide m-chlorophenyl hydrazine (CCCP, purple square), rapamycin (red diamond), and rotenone (green circle)] on the total number of granules per image using the JC-10 dye. Three replicate wells were evaluated for each data point; means (dots) and SD (vertical bars) are shown.

\begin{tabular}{|c|c|c|c|c|}
\hline & \multicolumn{2}{|c|}{ Granule intensity } & \multicolumn{2}{|c|}{ Total number of granules } \\
\hline & Average \pm SD & CV (\%) & Average \pm SD & CV $(\%)$ \\
\hline \multicolumn{5}{|c|}{ Time of incubation, min (with 1:200 dilution) } \\
\hline 15 & $37,300 \pm 2,600$ & 7.0 & $18,700 \pm 1,900$ & 10 \\
\hline 30 & $32,900 \pm 1,200$ & 3.6 & $34,500 \pm 2,200$ & 6.4 \\
\hline 60 & $24,600 \pm 2,400$ & 9.8 & $36,900 \pm 1,900$ & 5.1 \\
\hline 120 & $19,000 \pm 2,100$ & 11 & $16,100 \pm 3,500$ & 22 \\
\hline \multicolumn{5}{|c|}{$\mathrm{JC}-10$ reagent dilutions (at $30 \mathrm{~min}$ incubation) } \\
\hline 1:200 & $28,100 \pm 1,700$ & 6.0 & $34,500 \pm 2,200$ & 6.4 \\
\hline 1:400 & $19,700 \pm 2,200$ & 11 & $21,900 \pm 5,600$ & 26 \\
\hline $1: 800$ & $9,300 \pm 1,300$ & 14 & $19,300 \pm 9,300$ & 48 \\
\hline $1: 1,600$ & $420 \pm 120$ & 29 & $1,160 \pm 1,080$ & 93 \\
\hline
\end{tabular}

Results were calculated using one image per well in a 384-well plate using a $10 \times$ objective. Cells were stained as described in the text. Averages were derived from three wells on the same plate. 
Table 8. Multiparametric Assessment of the Effects of Compounds on the Mitochondrial Potential in iCell Neurons Using the JC-10 Assay

\begin{tabular}{l|c|c|c}
\multirow{2}{*}{ Parameter } & Control & Rotenone $(\mathbf{7} \mu \mathrm{M})$ & Z'-Factor \\
\cline { 2 - 4 } Total granule area per image & \multicolumn{2}{|c}{ Average \pm SD } & \\
\hline Mean granule area per cell & $49 \pm 00 \pm 12,600$ & $4,900 \pm 1,600$ & 0.44 \\
\hline Number of granules per image & $20,800 \pm 4,900$ & $2,300 \pm 150$ & 0.61 \\
\hline Number of granules per cell & $19 \pm 2.4$ & $2.1 \pm 0.5$ & 0.17 \\
\hline Average granule intensity & $25,900 \pm 1,000$ & $15,600 \pm 620$ & 0.52 \\
\hline Total cell Number & $1,094 \pm 67$ & $1,085 \pm 91$ & \\
\hline \multirow{2}{*yyyy}{} & $\mathbf{C C C P}$ & Rapamycin & Rotenone \\
\hline Total granule area per image & $0.35 \pm 0.08$ & $5.4 \pm 1.2$ & $11.0 \pm 10.8$ \\
\hline Mean granule area per cell & $0.35 \pm 0.08$ & $5.7 \pm 0.8$ & N.A. \\
\hline Number of granules per image & $0.38 \pm 0.06$ & $6.9 \pm 0.8$ & $8.6 \pm 2.9$ \\
\hline Number of granules per cell & $0.40 \pm 0.07$ & $7.5 \pm 0.4$ & $8.7 \pm 2.6$ \\
\hline Average granule intensity & $0.44 \pm 0.23$ & $8.5 \pm 3.5$ & N.A. \\
\hline
\end{tabular}

Results were calculated using one image per well in a $384-$ well plate using a $10 \times$ objective. Cells were cultured at 7,000/well for 6 days without treatment and then for $30 \mathrm{~min}$ in the presence of increasing concentrations of the compounds in DMSO vehicle. Averages and standard deviations were derived from eight wells on the same plate. $Z^{\prime}$-factor values were derived by comparing the results for control $(0.1 \% \mathrm{DMSO})$ and $7 \mu \mathrm{M}$ of rotenone from a single plate $(n=8)$. $\mathrm{EC}_{50}$ values were derived using the 4-parametric curve fit. N.A. means no fit was obtained to the data.

toxicity. It was found that the $\mathrm{EC}_{50}$ values for some compounds determined by the assays were higher than those reported in other studies that used primary neuronal cultures in vitro. For example, the $\mathrm{EC}_{50}$ value for rotenone was about 100 -fold greater in iCell Neurons in the live-cell imaging assay than those reported in primary rat neurons. ${ }^{39}$ However, the $\mathrm{EC}_{50}$ values for methylmercury was similar to that reported for a rat neuronal cell model. ${ }^{40}$ Interaction of neuronal cells with astrocytes and other cells may increase the sensitivity of the assay, so future improvement of the assay may include a coculture system of neurons and astrocytes.

It is also likely that additional assays and read-outs would be beneficial to the overall utility of the system. For example, the mitochondrial potential assay using JC-10 demonstrated that it can be a potentially useful follow-up mechanistic evaluation step. Information from this assay is complementary to neurite outgrowth phenotype characterizations. Clear concentrationdependent responses were observed with this assay; however, further improvements are needed to increase assay precision and robustness. In addition, nonhighcontent screening assays measuring, for example, neuronal activation, calcium ion flux, or ion channel activity could enable functional screening for neurotoxicity. ${ }^{41}$ Such assays will be even more useful for addressing neuronal signaling or disease phenotypes in more advanced iPSC-derived models such as dopaminergic neurons, or specific patient-derived cells.

In summary, the iPSC-derived neuronal cell model combined with high-content imaging-based assays presented in this study shows promise as a sensitive

segmented into individual cells by nuclear staining and then live (positive) or dead (negative) cells are determined by the intensity of the Calcein AM signal in the neuronal bodies.

Importantly, the performance of the live-cell imaging assay with Calcein AM is highly comparable to traditional fixed-cell assays with neuronal markers $\beta$-III tubulin and MAP2. While it is not surprising that in highly homogenous and pure cell cultures, such as iCell Neurons, any marker that is able to visualize neuronal bodies and outgrowth would perform well, the Calcein AM assay offers unique advantages in terms of ease-of-use and information output, which enables phenotype characterization according to cell viability under experimental conditions. In addition, cells may be fixed and stored for follow up analysis with any number of additional markers.

It should be acknowledged that even with the proposed improvements and optimizations, this in vitro model system has limitations with respect to neuronal toxicity hazard detection and identification of potential mechanisms. Since only a very limited set of compounds was tested, it was not possible to determine assay predictivity, sensitivity, and specificity. Testing an extended set of compounds needs to be performed to determine these parameters. We also note that the proposed assays may not distinguish well between neurotoxic effects and general cyto- and reproducible tool for assessing changes in neuronal viability and morphology. While there are a number of limitations, further development of the methods and models will increase the utility of this in vitro tool for screening of potential neurotoxic hazards of chemicals.

\section{ACKNOWLEDGMENTS}

The authors would like to thank CDI for providing iCell Neurons. The authors also wish to thank Susan DeLaura and Coby Carlson (CDI), and Kristen Ryan (NIEHS) for suggestions and comments. This work was supported, in part, by grants from US EPA (STAR RD83516601 and STAR RD-83574701), and NIH (P42 ES005948).

\section{DISCLOSURE STATEMENT}

O. Sirenko, J. Hesley, and E.F. Cromwell were employed by Molecular Devices, LLC, which manufactures the imaging instruments and software used in these studies.

\section{REFERENCES}

1. May M: Disturbing behavior: neurtotoxic effects in children. Environ Health Perspect 2000;108:A262-A267.

2. Chang LW: Principles of Neurotoxicology. M. Dekker, New York, NY, 1994. 
3. Travis LB, Fossa SD, Sesso HD, et al.: Chemotherapy-induced peripheral neurotoxicity and ototoxicity: new paradigms for translational genomics. J Nat/ Cancer Inst 2014;106:dju044.

4. Kola I, Landis J: Can the pharmaceutical industry reduce attrition rates? Nat Rev Drug Discov 2004;3:711-715.

5. Hartung T: Toxicology for the twenty-first century. Nature 2009;460:208-212.

6. Bal-Price AK, Hogberg HT, Buzanska L, Coecke S: Relevance of in vitro neurotoxicity testing for regulatory requirements: challenges to be considered. Neurotoxicol Teratol 2010;32:36-41.

7. Harrill JA, Freudenrich TM, Machacek DW, Stice SL, Mundy WR: Quantitative assessment of neurite outgrowth in human embryonic stem cell-derived hN2 cells using automated high-content image analysis. Neurotoxicology 2010;31:277-290.

8. Gotte M, Hofmann G, Michou-Gallani Al, Glickman JF, Wishart W, Gabriel D: An imaging assay to analyze primary neurons for cellular neurotoxicity. J Neurosci Methods 2010;192:7-16.

9. Al-Ali H, Schurer SC, Lemmon VP, Bixby JL: Chemical interrogation of the neuronal kinome using a primary cell-based screening assay. ACS Chem Biol 2013;8:1027-1036.

10. Radio NM, Mundy WR: Developmental neurotoxicity testing in vitro: models for assessing chemical effects on neurite outgrowth. Neurotoxicology 2008;29:361-376.

11. Radio NM, Breier JM, Shafer TJ, Mundy WR: Assessment of chemical effects on neurite outgrowth in $\mathrm{PC} 12$ cells using high content screening. Toxicol Sci 2008;105:106-118.

12. Breier JM, Radio NM, Mundy WR, Shafer TJ: Development of a high-throughput screening assay for chemical effects on proliferation and viability of immortalized human neural progenitor cells. Toxicol Sci 2008;105:119-133.

13. Young A, Machacek DW, Dhara SK, et al:: Ion channels and ionotropic receptors in human embryonic stem cell derived neural progenitors. Neuroscience 2011;192:793-805.

14. Dragunow M: High-content analysis in neuroscience. Nat Rev Neurosci 2008:9:779-788.

15. Harrill JA, Robinette $B L$, Freudenrich $T$, Mundy WR: Use of high content image analyses to detect chemical-mediated effects on neurite sub-populations in primary rat cortical neurons. Neurotoxicology 2013;34:61-73.

16. Efthymiou A, Shaltouki A, Steiner JP, et al.: Functional screening assays with neurons generated from pluripotent stem cell-derived neural stem cells. $J$ Biomol Screen 2014;19:32-43.

17. Chen G, Gulbranson DR, Hou Z, et al:: Chemically defined conditions for human iPSC derivation and culture. Nat Methods 2011;8:424-429.

18. Hu BY, Weick JP, Yu J, et al:: Neural differentiation of human induced pluripotent stem cells follows developmental principles but with variable potency. Proc Natl Acad Sci U S A 2010;107:4335-4340.

19. Anson BD, Kolaja KL, Kamp TJ: Opportunities for use of human iPS cells in predictive toxicology. Clin Pharmacol Ther 2011;89:754-758.

20. Haythornthwaite A, Stoelzle $S$, Hasler $A$, et al:: Characterizing human ion channels in induced pluripotent stem cell-derived neurons. J Biomol Screen 2012;17:1264-1272.

21. Chai $X$, Dage $J L$, Citron $M$ : Constitutive secretion of tau protein by an unconventional mechanism. Neurobiol Dis 2012;48:356-366.

22. Whitemarsh RC, Strathman MJ, Chase LG, et al.: Novel application of human neurons derived from induced pluripotent stem cells for highly sensitive botulinum neurotoxin detection. Toxicol Sci 2012;126:426-435.

23. Dage JL, Colvin EM, Fouillet $A$, et al.: Pharmacological characterisation of ligand- and voltage-gated ion channels expressed in human iPSC-derived forebrain neurons. Psychopharmacology 2014;231:1105-1124.

24. Guo L, Abrams RM, Babiarz JE, et al:: Estimating the risk of drug-induced proarrhythmia using human induced pluripotent stem cell-derived cardiomyocytes. Toxicol Sci 2011;123:281-289.

25. Sirenko 0, Hesley J, Rusyn I, Cromwell EF: High-content assays for hepatotoxicity using induced pluripotent stem cell-derived cells. Assay Drug Dev Technol 2014;12:43-54.

26. Xu X, Lei Y, Luo J, et al:: Prevention of beta-amyloid induced toxicity in human iPS cell-derived neurons by inhibition of Cyclin-dependent kinases and associated cell cycle events. Stem Cell Res 2013;10:213-227.
27. Hu K, Yu J, Suknuntha $\mathrm{K}_{1}$ et al:: Efficient generation of transgene-free induced pluripotent stem cells from normal and neoplastic bone marrow and cord blood mononuclear cells. Blood 2011;117:e109-e119.

28. Katsetos $C D$, Herman MM, Mork SJ: Class III beta-tubulin in human development and cancer. Cell Motil Cytoskeleton 2003;55:77-96.

29. Neve RL, Harris P, Kosik KS, Kurnit DM, Donlon TA: Identification of cDNA clones for the human microtubule-associated protein tau and chromosomal localization of the genes for tau and microtubule-associated protein 2. Brain Res 1986;387: 271-280.

30. Lammer EJ, Chen DT, Hoar RM, et al:: Retinoic acid embryopathy. N Engl J Med 1985;313:837-841.

31. Clarkson TW, Magos L, Myers GJ: The toxicology of mercury-current exposures and clinical manifestations. N Engl J Med 2003;349:1731-1737.

32. Swarnkar S, Singh S, Sharma S, Mathur R, Patro IK, Nath C: Rotenone induced neurotoxicity in rat brain areas: a histopathological study. Neurosci Lett 2011; 501:123-127.

33. Gao HM, Hong JS, Zhang W, Liu B: Distinct role for microglia in rotenoneinduced degeneration of dopaminergic neurons. J Neurosci 2002;22:782-790.

34. Baker LH, Opipari MI, Wilson H, Bottomley R, Coltman CA, Jr. Mitomycin C, vincristine, and bleomycin therapy for advanced cervical cancer. Obstet Gynecol 1978;52:146-150

35. Reers $M$, Smiley ST, Mottola-Hartshorn $C$, Chen $A$, Lin $M$, Chen LB. Mitochondrial membrane potential monitored by JC-1 dye. Methods Enzymol 1995;260:406-417.

36. Forgacs B, Merhav HJ, Lappin J, Mieles L: Successful conversion to rapamycin for calcineurin inhibitor-related neurotoxicity following liver transplantation. Transplant Proc 2005;37:1912-1914.

37. McNeish J, Roach M, Hambor J, et al.: High-throughput screening in embryonic stem cell-derived neurons identifies potentiators of alpha-amino-3-hydroxyl5-methyl-4-isoxazolepropionate-type glutamate receptors. J Biol Chem 2010; 285:17209-17217.

38. Breier JM, Gassmann $K_{1}$ Kayser $R$, et al:: Neural progenitor cells as models for high-throughput screens of developmental neurotoxicity: state of the science. Neurotoxicol Teratol 2010;32:4-15

39. Emmrich JV, Hornik TC, Neher JJ, Brown GC: Rotenone induces neuronal death by microglial phagocytosis of neurons. FEBS J 2013;280:5030-5038.

40. Kunimoto M: Methylmercury induces apoptosis of rat cerebellar neurons in primary culture. Biochem Biophys Res Commun 1994;204:310-317.

41. Zhang H, Dougherty PM: Enhanced excitability of primary sensory neurons and altered gene expression of neuronal ion channels in dorsal root ganglion in paclitaxel-induced peripheral neuropathy. Anesthesiology 2014;120:1463-1475.

Address correspondence to: Oksana Sirenko, PhD Molecular Devices, LLC 1311 Orleans Drive Sunnyvale, CA 94089

E-mail: oksana.sirenko@moldev.com

Abbreviations Used

$$
\begin{aligned}
\mathrm{CCCP} & =\text { carbonyl cyanide } \mathrm{m} \text {-chlorophenyl hydrazine } \\
\mathrm{CV} & =\text { coefficient of variation } \\
\mathrm{DAPI} & =4^{\prime}, 6 \text {-diamidino-2-phenylindole } \\
\mathrm{DMSO} & =\text { dimethyl sulfoxide } \\
\mathrm{FBS} & =\text { fetal bovine serum } \\
\mathrm{FITC} & =\text { fluorescein isothiocyanate } \\
\mathrm{IPSC} & =\text { induced pluripotent stem cells } \\
\mathrm{PBS} & =\text { phosphate buffered saline } \\
\mathrm{SD} & =\text { standard deviation } \\
\text { TRITC } & =\text { tetramethyl rhodamine isothiocyanate }
\end{aligned}
$$

